A Colour Atlas of Tropical Medicine and Parasitology

By W. Peters and H. M. Gilles. Wolfe Medical Atlases17. Pp. 416, hard cover, illustrated. London: Wolfe Medical Publications, 1976. $£ 18.00$.

Wolfe Medical Atlases are to be congratulated on the seventeenth in their series which is devoted to tropical medicine and parasitology. Few conditions lend themselves so well in medicine to this highly pictorial representation and the authors have presented beautifully reproduced macroscopic and microscopic pictures opposite some simple but clear statements. In deciding what conditions they should consider as tropical they have wisely included a proportion of the rare, but along with this the universal problems of malnutrition and such common but fatal diseases as measles. The book is well set out with useful reference tables and lists at the end of the volume.

The authors in their introduction state... 'It should be helpful to medical and paramedical workers in the tropics who need an accurate diagnostic guide to a wide range of diseases'. Surely they must have had their tongue in their cheeks when they made this remark about a book that costs $£ 18$ for 416 pages. Books that cost $4 \cdot 3$ p a page are surely out of the reach of the vast majority of students or health workers and even libraries may question whether expenditure at this level is justified. This is yet another book through which we in the West can study the conditions of the less fortunate people in developing countries, but at this price it is surely of little relevance to them.

\section{The Multiple Choice Question in Medicine}

By John Anderson. Pp. viii + 152, soft cover, illustrated. Tunbridge Wells: Pitman Medical, 1976. $£ 3.00$.

This book provides a useful introduction to multiple choice questions, and should prove helpful to those attempting to write multiple choice question papers for the first time and also to students.

Chapters are provided on types of multiple choice, setting of multiple choice questions, candidate responses, marking, evaluation, revision of questions and hints to candidates.
These provide satisfactory brief reviews with particular emphasis on the multiple true/false variety. The bibliography is good and $50 \%$ of the book provides a considerable number of examples.

However, one might take issue with the author on his claim for multiple choice questions to be capable of evaluating higher taxonomic areas than core knowledge. One would also have liked to have seen more stress on the evaluation of validity of question in relation to the material being tested and, for example, the difficulty in developing good clinical questions versus biochemical questions.

However, as an introduction it is a useful addition, though for 60 pages of text and examples of 150 multiple choice questions, the price of $£ 3.00$ seems a little excessive.

\section{On Science and Surgery}

By Michael Woodruff. Pp. viii +154 , hard or soft cover.

Edinburgh: Edinburgh University Press, 1977. $£ 4.00$ cloth cover; $£ 1.50$ paper cover.

Sir Michael Woodruff, as well as being a distinguished surgical teacher, a pioneer of organ transplantation and one of the handful of surgeons to be made a Fellow of the Royal Society, is also a leading medical philosopher. His writings and lectures, as well as his personal contacts, have had a profound effect on the attitudes of many young men in surgical training towards the deeper implications of their work. Now at the beginning of his Emeritus Professorship of Surgery at the University of Edinburgh, it will be a pleasure for his many friends and colleagues to see the publication of this collection of a number of his addresses on medical education, practice and research given over the last quarter of a century. Of the eleven addresses, most were given to nonspecialist audiences but three which deal with aspects of immunobiology and cancer are rather more technical but are still well within the ambit of a general audience. The reviewer recommends all his fellow Professors of Surgery to read the first lecture, on the University and Surgery, but he hopes that a very wide public, both medical and interested laity, will take the opportunity of studying this profound collection of wisdom.

\title{
Correspondence
}

SIR-Gilmore and his associates (March, 1977) recently reported a case of acute myeloid leukaemia arising during azathioprine treatment of rheumatoid arthritis in a 73-yearold woman. They claim that this is the third such case on record; the other two cases were reported by Silverglied and Schrier (1974).

It is true that the occurrence of myeloid leukaemia in patients treated with azathioprine for non-malignant illness is infrequent. However, four additional cases have been reported. As a matter of fact, it was Cobau, Sheon and Kirsner (1973) and not Silverglied and Schrier (1974) who described the first case of acute leukaemia in a 67-year-old man with rheumatoid arthritis, who was treated with azathioprine (among other drugs) over a period of 5 years. Seidenfeld et al. (1976) reported two cases of acute leukaemia (in a 57-year-old woman and a 68-year-old man) following long-term treatment with azathioprine for severe rheumatoid arthritis. Finally, Battin et al. (1976) reported a case of chronic myeloid leukaemia in a 15 -year-old boy with chronic nephropathy receiving azathioprine for more than two years.

\section{References}

Battin, J., Hehunstre, J.P., Bui, N.B., Auzerie, J. \& Colle, M. (1976) Leucémie myéloïde chronique (L.M.C.) après traitement immuno-dépresseur pour néphrophathie chronique. Nouvelle Presse Médicale, 5, 2632.

Cobau, C.D., Sheon, R.P. \& KirSner, A.B. (1973) Immunosuppressive drugs and acute leukemia. Annals of Internal Medicine, 79, 131.

Gilmore, I.T., Holden, G. \& Rodan, K.S. (1977) Acute leukaemia during azathioprine therapy. Postgraduate Medical Journal, 53, 173.

Seidenfeld, A.M., Smythe, H.A., Ogryzlo, M.A., UrowITZ, M.B. \& DotTen, D.A. (1976) Acute leukemia in rheumatoid arthritis treated with cytotoxic agents. Journal of Rheumatology, 3, 295.

Silverglied, A.J. \& SChrier, S.L. (1974) Acute myelogenous leukemia in two patients treated with azathioprine for nonmalignant diseases. American Journal of Medicine, 57,885 .

811 Clifford Avenue,

Jata S. Ghosh Ardmore,

Pennsylvania 19003 ,

U.S.A. 